\title{
Hepatoma-derived growth factor/nucleolin axis as a novel oncogenic pathway in liver carcinogenesis
}

\author{
San-Cher Chen ${ }^{1, *}$, Tsung-Hui Hu${ }^{2, *}$, Chao-Cheng Huang ${ }^{3}$, Mei-Lang Kung ${ }^{4}$, \\ Tian-Huei $\mathrm{Chu}^{5}$, Li-Na $\mathrm{Yi}^{2}$, Shih-Tsung Huang, ${ }^{6}$, Hoi-Hung Chan ${ }^{7}$, Jiin-Haur \\ Chuang $^{8}$, Li-Feng Liu ${ }^{9}$, Han-Chung Wu ${ }^{6,10}$, Deng-Chyang Wu ${ }^{11}$, Min-Chi Chang ${ }^{12}$, \\ Ming-Hong Tai ${ }^{1,5,6}$ \\ ${ }^{1}$ Center for Neuroscience, National Sun Yat-Sen University, Kaohsiung 804, Taiwan \\ ${ }^{2}$ Division of Hepato-Gastroenterology, Chang Gung Memorial Hospital-Kaohsiung Medical Center, Chang Gung University \\ College of Medicine, Kaohsiung 833, Taiwan \\ ${ }^{3}$ Department of Pathology, Chang Gung Memorial Hospital-Kaohsiung Medical Center, Chang Gung University College of \\ Medicine, Kaohsiung 833, Taiwan \\ ${ }^{4}$ Department of Chemistry, National Sun Yat-Sen University, Kaohsiung 804, Taiwan \\ ${ }^{5}$ Institute of Biomedical Sciences, National Sun Yat-Sen University, Kaohsiung 804, Taiwan \\ ${ }^{6}$ Graduate Program in Marine Biotechnology, National Sun Yat-Sen University, Kaohsiung 804, Taiwan \\ ${ }^{7}$ Division of Gastroenterology, Department of Internal Medicine, Kaohsiung Veterans General Hospital, Kaohsiung 813, Taiwan \\ ${ }^{8}$ Department of Pediatric Surgery, Chang Gung Memorial Hospital-Kaohsiung Medical Center, Chang Gung University College \\ of Medicine, Kaohsiung 833, Taiwan \\ ${ }^{9}$ Department of Biological Science \& Technology, I-Shou University, Kaohsiung 840, Taiwan \\ ${ }^{10}$ Institute of Cellular and Organismic Biology and Genomics Research Center, Academia Sinica, Taipei 115, Taiwan \\ ${ }^{11}$ Center for Stem Cell Research and Division of Gastroenterology, Department of Internal Medicine, Kaohsiung Medical \\ University, Kaohsiung 807, Taiwan \\ ${ }^{12}$ Division of Colorectal Surgery, Department of Internal Medicine, Kaohsiung Veterans General Hospital, Kaohsiung 813, Taiwan \\ *These authors have contributed equally to this work
}

Correspondence to:

Min-Chi Chang, e-mail: smartzhang0205@gmail.com

Ming-Hong Tai, e-mail: minghongtai@gmail.com

Keywords: hepatoma-derived growth factor, nucleolin, hepatocellular carcinoma, tumour progression

Received: September 15, $2014 \quad$ Accepted: April 07, $2015 \quad$ Published: April 17, 2015

\section{ABSTRACT}

Hepatoma-derived growth factor (HDGF) overexpression is involved in liver fibrosis and carcinogenesis. However, the receptor(s) and signaling for HDGF remain unclear. By using affinity chromatography and proteomic techniques, nucleolin (NCL) was identified and validated as a HDGF-interacting membrane protein in hepatoma cells. Exogenous HDGF elicited the membrane NCL accumulation within 0.5 hour by protein stabilization and transcriptional NCL upregulation within $\mathbf{2 4}$ hours. Blockade of surface NCL by antibodies neutralization potently suppressed HDGF uptake and HDGF-stimulated phosphatidylinositol 3-kinase (PI3K)/Akt signaling in hepatoma cells. By using rescectd hepatocellular carcinoma (HCC) tissues, immunohistochemical analysis revealed NCL overexpression was correlated with tumour grades, vascular invasion, serum alphafetoprotein levels and the poor survival in HCC patients. Multivariate analysis showed NCL was an independent prognostic factor for survival outcome of HCC patients after surgery. To delineate the role of NCL in liver carcinogenesis, ectopic NCL overexpression promoted the oncogenic behaviours and induced PI3K/Akt activation in hepatoma cells. Conversely, NCL knockdown by RNA interference attenuated the oncogenic behaviours and PI3K/Akt signaling, which could be partially rescued by exogenous HDGF supply. In summary, this study provides the first evidence that surface NCL transmits the oncogenic signaling of HDGF and facilitates a novel diagnostic and therapeutic target for HCC. 


\section{INTRODUCTION}

Hepatocellular carcinoma (HCC) is the fifth most common cancer and the third leading cause of cancer death worldwide [1]. Early stage HCC is frequently asymptomatic that most HCC patients are diagnosed at intermediate or advanced stages. Despite the recent advances in biomedical sciences, the molecular mechanism underlying liver carcinogenesis remains far from elucidated. Hence, a major clinical challenge is to identify the novel molecular markers for HCC diagnosis and therapy.

Hepatoma-derived growth factor (HDGF) is a protein of 240 amino-acid isolated from the cultured supernatants of human hepatoma cells [2]. HDGF is composed of a highly conserved $\mathrm{N}$-terminal 100 residues HATH (homologous to the amino terminus of HDGF) domain and a variable C-terminal 140 residues (C140) domain. With two bipartite nuclear localization sequences, HDGF is mainly localized in nucleus and stimulates the proliferation in various types of cells including fibroblasts, endothelial cells and hepatoma cells [3]. HDGF is overexpressed in a variety of human cancers and correlated with poor prognosis in patients of HCC [4], breast cancer [5], non-small cell lung cancer [6], colorectal cancer [7], gastrointestinal stromal tumours [8], pancreatic cancer [9], glioblastoma [10] and oral cancer [11]. Recently, HDGF overexpression has also been delineated to contribute to liver fibrosis [12], epithelial-mesenchymal transition and metastasis $[5,13]$. However, the receptor(s) and signaling pathway for HDGF remain elusive. The present study characterized surface nucleolin (NCL) as a receptor for HDGF and evaluated the prognostic and therapeutic potential of NCL for HCC.

\section{RESULTS}

\section{NCL is an HDGF-binding membrane protein in hepatoma cells}

To search for the plausible HDGF receptor(s) in HCC cells, affinity column chromatography and mass spectrum-based proteomic approaches were employed to identify the HDGF-interacting proteins from the membrane fraction of hepatoma SK-Hep-1 cells, which was validated by immunoblot analysis (data not shown). After affinity column chromatography, silver staining analysis revealed several distinct protein bands (from 55-95 kDa) present only in elutes from HDGF, but not C140, affinity column (Figure 1A). By using liquid chromatography tandem mass spectrometry analysis, peptide identification of these excised bands showed that one of the major protein band at $77 \mathrm{kDa}$ was characterized as nucleolin (NCL) with a total score of 948 and $32 \%$ sequence coverage to human NCL in NCBI database (accession number: gi189306; Figure 1B, Supplementary
Table 1 and 2). A total of 21 peptide sequences were matched to human NCL sequence. Moreover, immunoblot analysis using an anti-NCL antibody further confirmed the enrichment of NCL in the elutes from HDGF affinity column (Figure 1C). Thus, the proteomic studies suggested that NCL is a HDGF-interacting membrane protein in hepatoma cells.

\section{HDGF interacts with surface NCL via heparin-binding HATH domain}

To confirm the interaction of HDGF with surface NCL, immunofluorescence analysis was used to investigate the NCL distribution after exposure to various recombinant HDGF proteins. It was found that exogenous HDGF supply was co-localized with NCL in cytoplasm/plasma membrane of hepatoma cells (Figure 1D-1E). In contrast, exogenous C140 supply exhibited no significant NCL co-localization. To further validate whether such interaction indeed took place in membrane, we used a membrane-labeling carbocyanine dye, Dil, in immunofluorescent analysis [14, 15]. It was observed that DiI staining was co-localized with more than $80 \%$ of 6xHis-tagged HDGF immunostaining at surface of hepatoma cells (Supplementary Figure 1A). Similarly, about $10 \%$ of NCL immunostaining was co-localized with Dil staining in HDGF-treated cells (Supplementary Figure 1B). These results indicate HDGF binds to NCL in plasma membrane.

Because the heparin-binding HATH domain of HDGF is responsible for the cell surface binding [16], we investigated the influence of excessive heparin on the interaction between HDGF and NCL by co-IP assay. Heparin supply dose-dependently attenuated the binding between HDGF and NCL without affecting the NCL level (Figure 1F). To dissect the HDGF-binding domain within NCL, recombinant NCL proteins encompassing the N-terminal domain (residues 1-284), the central domain (residues 285-645), and the C-terminal argnineglycine-glycine domain (residues 646-707) were generated for GST pull down assay. The N-terminal domain of NCL was responsible for the interaction between NCL and HDGF (Figure 1G). Together, these results indicate that HDGF directly interacts with cell surface NCL through its HATH domain.

\section{Exogenous HDGF promotes the translocation and enhances stability of NCL in plasma membrane of hepatoma cells}

Although known as an abundant nuclear protein, NCL shuttles among various subcellular compartments from nucleus, cytoplasm and plasma membrane [17]. To investigate whether HDGF regulated the distribution and expression of NCL, flow cytometry analysis was performed to evaluate the cell surface NCL expression 
A

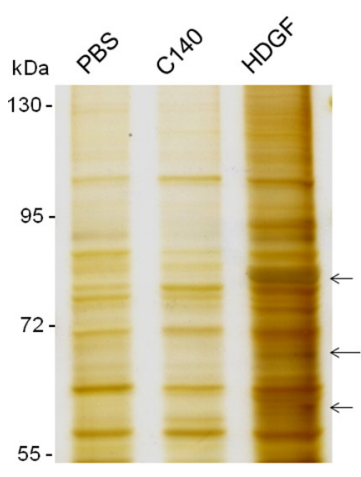

B

1 MVKLAKAGKN QGDPKKMAPP PKEVEEDSED EEMSEDEEDD SSGEBVVIPQ 51 KKGKKAAATS AKKVVVSPTK KVAVATPAKK AAVTPGKKAA ATPAKKTVTP 101 AKAVTTPGKK GATPGKALVA TPGKKGAAIP AKGAKNGKNA KKEDSDEEED 151 DDSEEDEEDD EDEDEDEDEI EPAAMKAAAA APASEDEDDE DDEDDEDDDD 201 DEEDDSEEEA METTPAKGKK AAKVVPVKAK NVAEDEDEEE DDEDEDDDDD 251 EDDEDDDDED DEEEEEEEEE EPVKEAPGKR KKEMAKQKAA PEAKKQKVEG 301 TEPTTAFNLF VGNLNFNKSA PELKTGISDV FAKNDLAVVD VRIGMTRKFG 351 YVDFESAEDL EKALELTGLLK VFGNEIKLEK PKGKDSKKER DARTLLAKNL 401 PYKVTQDELK EVFEDAAEIR LVSKDGKSKG IAYIEFKTEA DAEKTFEEKQ 451 GTEIDGRSIS LYYTGEKGQN QDYRGGKNST WSGESKTLVL SNLSYSATEE 501 TLQEVVEEKAT FIKVPQNQNG KSKGYAFIEF ASFEDAKEAL NSCNKREIEG 551 RAIRLELQGP RGSPNARSQP SKTLFVKGLS EDTTEETLKE SEDGSVRARI 601 VTDRETGSSK GFGFVDFNSE EDAKEAMEDG EIDGNKVTID WAKPKGEGGF 651 GGRGGGRGGE GGRGGGRGGR GGFGGRGRGG FGGRGGFRGG RGGGGDHKPQ 701 GKKTKEE

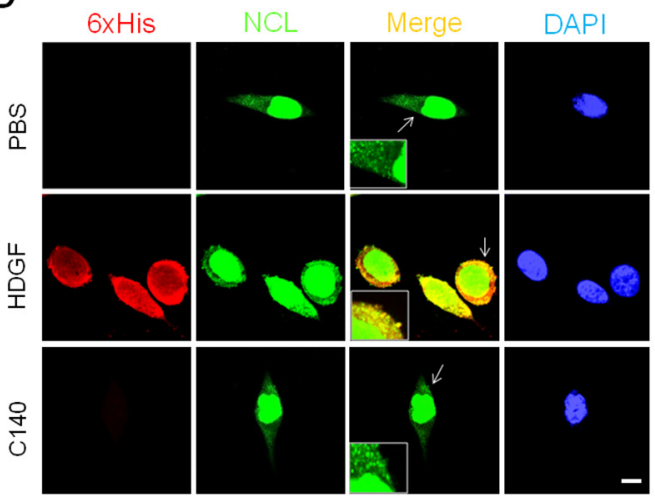

$\mathbf{F}$

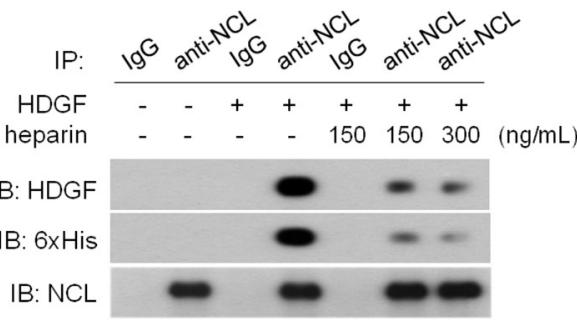

E

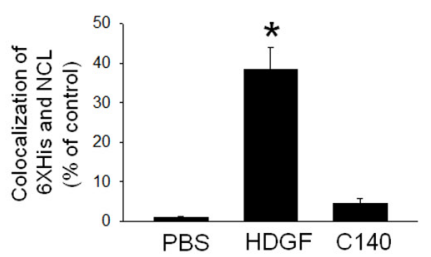

G
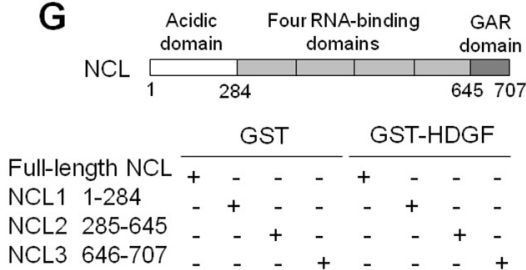

C

IB: NCL

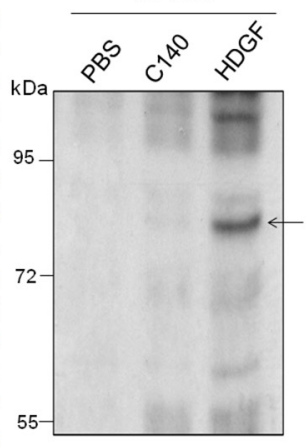

5

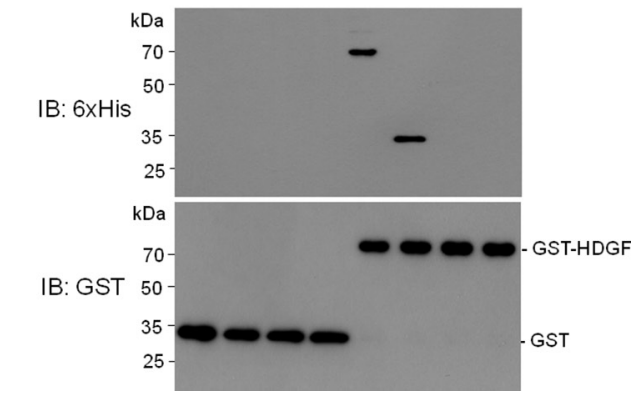

Figure 1: Characterization of NCL as a HDGF-binding membrane protein. A. Silver staining analysis of the eluted proteins from different affinity columns after separation by $10 \%$ SDS-PAGE. The protein bands of interest (asterisk) were digested and identified by LC-MS/MS spectra and NCBI database. B. NCL as a HDGF-binding membrane protein. Peptide identification revealed several peptides sequences in red matched in NCL protein. C. Immunoblot analysis of the eluted proteins from different affinity columns using an anti-NCL antibody. The arrow indicated the presence of NCL. D. Co-localization of exogenous HDGF with NCL in SK-Hep-1 cells by immunofluorescence analysis. After treatment with exogenous HDGF and C140 (10 ng/mL) for 4 hours, cells were permeabilized by Triton X-100 and stained with anti-6xHis (red) and anti-NCL antibodies (green). Bar, $20 \mu \mathrm{m}$. E. Quantification of co-localization of 6xHis and NCL immunostaining. Data were analyzed using WCIF-Image J software and presented as mean \pm SD percentages of the control. ${ }^{*} P<0.05$ versus control. F. Competition of HDGF binding to NCL by heparin. Membrane proteins of SK-Hep-1 cells were incubated with recombinant HDGF $(500 \mathrm{ng} / \mathrm{mL})$ and heparin $(150$ and $300 \mathrm{ng} / \mathrm{mL})$ for 4 hours. The complex was immunoprecipitated with an anti-NCL antibody and immunoblotted with various antibodies. G. GST pull down assay. GST-fused HDGF was added to 6xHis-tagged NCL residues 1-707, residues 1-284, residues 285-645, or residues 646-707 bound to glutathione-Sepharose beads. Proteins on the beads were immunoblotted with anti-6xHis and anti-GST antibodies.

in HDGF-treated SK-Hep-1 cells. HDGF treatment increased the cell surface NCL level in SK-Hep-1 cells (Figure 2A). Subsequently, a cycloheximide (CHX)-chase experiment was performed to determine the stability of membrane NCL. It was found that exogenous HDGF supply significantly extended the half-life of membrane NCL from 1 hour to 3 hours (Figure 2B). By using various subcellular fractions, the time-series studies indicated that HDGF elicited the membrane translocalization of NCL from cytoplasm to plasma membrane in as early as 
15 minutes (Figure 2C). To investigate whether HDGF directly regulates NCL expression, quantitative RT-PCR and immunoblot analysis revealed that HDGF dosedependently increased NCL mRNA and protein levels in SK-Hep-1 cells (Figure 2D-2E). Moreover, ectopic HDGF overexpression by infection with adenovirus vectors encoding HDGF (Ad-HDGF) significantly increased the
NCL protein level, whereas HDGF silencing by infection with adenovirus vectors encoding HDGF small interfering RNA (Ad-HDGF RNAi) decreased the NCL protein level in SK-Hep-1 cells (Figure 2F). Therefore, HDGF promotes the translocation and stability of surface NCL during early exposure and ultimately induces NCL upregulation in hepatoma cells after longer treatment.
A

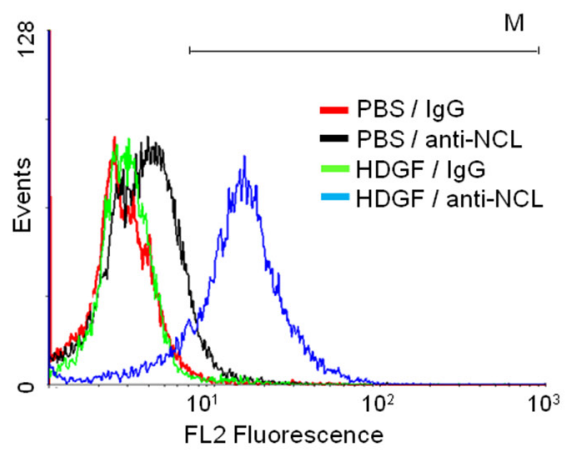

C

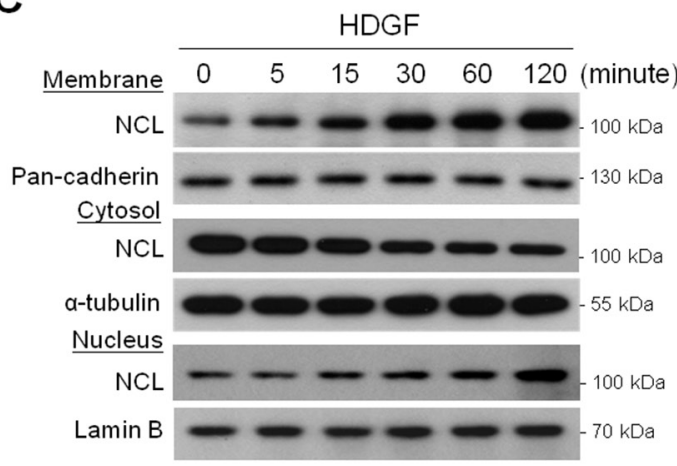

D

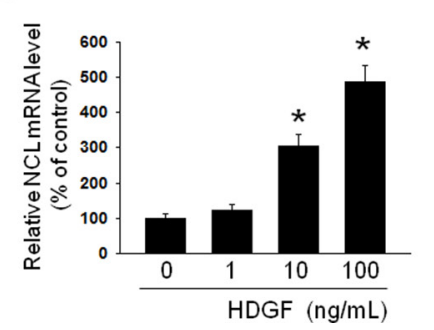

B

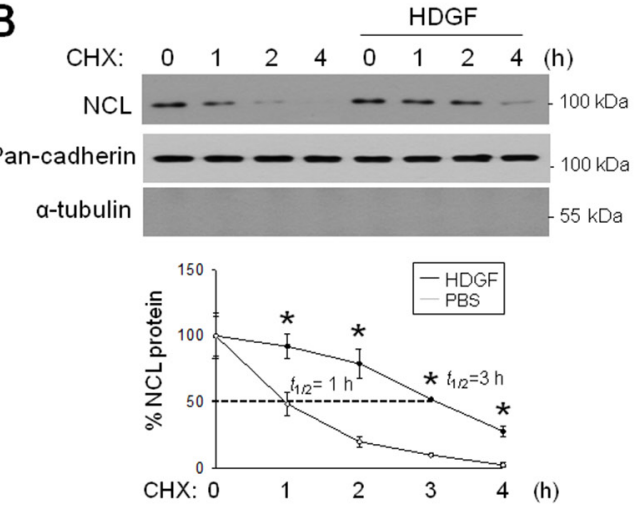

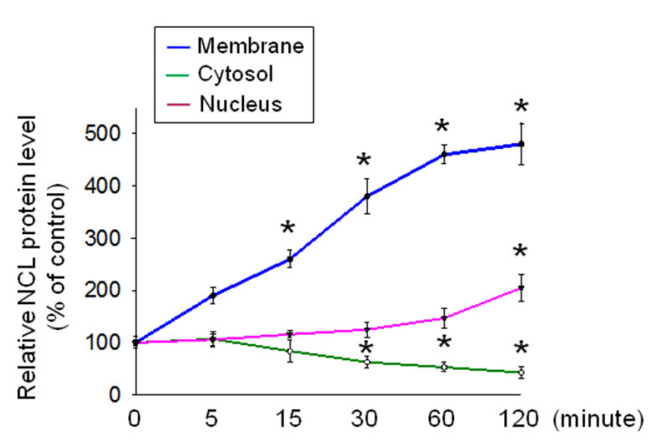

$\mathbf{F}$

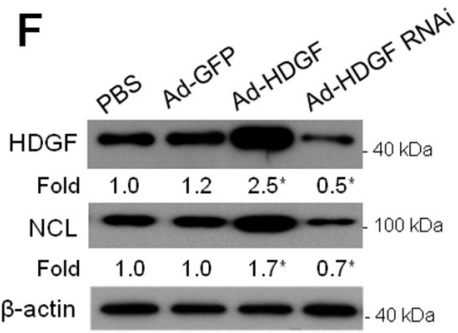

Figure 2: Effect of exogenous HDGF on the membrane translocation and the protein stability of NCL in hepatoma cells. A. Flow cytometry analysis of cell surface NCL expression after HDGF treatment. After treatment with HDGF (10 ng/mL) for 24 hours, cells were fixed in paraformaldehyde solution. Plasma membrane NCL was stained with an anti-NCL antibody and evaluated by flow cytometry analysis. B. Effect of HDGF on NCL stability in plasma membrane. Cells were simultaneously treated with HDGF $(10 \mathrm{ng} / \mathrm{mL})$ and cycloheximide $(\mathrm{CHX}, 50 \mu \mathrm{g} / \mathrm{mL})$ for $1-4$ hours. The protein stability of the purified membrane NCL (from $2 \times 10^{7}$ cells) was monitored by immunoblot analysis. C. Time-dependent effect of HDGF on NCL distribution in various subcellular fractions in SKHep-1 cells. Plasma membrane, cytosol and nuclear NCL were immunoblotted using an anti-NCL antibody. D. Dose effect of HDGF on NCL mRNA expression in SK-Hep-1 cells. After treatment with HDGF for 24 hours, total RNA was isolated for quantitative RT-PCR analysis of NCL mRNA level. E. Dose effect of HDGF on NCL protein expression in SK-Hep-1 cells. After treatment with HDGF for 24 hours, protein extracts were isolated for immunoblot analysis of NCL protein level. F. Effect of HDGF modulation on NCL protein level by immunoblot analysis. After infection with adenovirus vectors at an MOI of 200 for $72 \mathrm{~h}$, cells were harvested for detecting the protein expression of HDGF and NCL. The data are presented as the mean \pm SD as percentages of the control. $* P<0.05$ versus control. 
To further confirm the function of NCL as a cell surface receptor for $\mathrm{HDGF}$, we examined whether neutralization of surface NCL influenced the HDGF uptake of hepatoma cells. By using immunofluorescence analysis, it was shown that application of anti-NCL neutralizing antibodies prominently reduced intake of HDGF in hepatoma cells (Figure 3A). Moreover, by using fluorescent-labeling HDGF, the cellular uptake assay revealed that prior NCL blockage significantly depleted the fluorescence in HDGF-treated hepatoma cells (Figure 3B). Because HDGF induces the activation of phosphatidylinositol 3-kinase (PI3K)/Akt pathway [18], we examined the effect of NCL neutralization on
HDGF-stimulated PI3K/Akt signaling by immunoblot analysis. It was shown that application of anti-NCL antibodies, but not control IgG, abrogated the HDGFinduced PI3K/Akt phosphorylation in hepatoma cells (Figure 3C). These results reveal that surface NCL is involved in the cellular HDGF uptake as well as HDGFstimulated PI3K/Akt signaling in hepatoma cells.

\section{Elevated NCL expression is correlated with HCC progression in human HCC tissues}

HDGF overexpression is correlated with tumor progression and poor survival outcome for $\mathrm{HCC}$

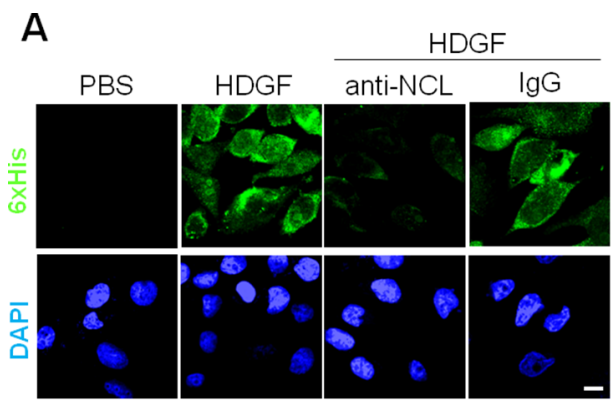

B
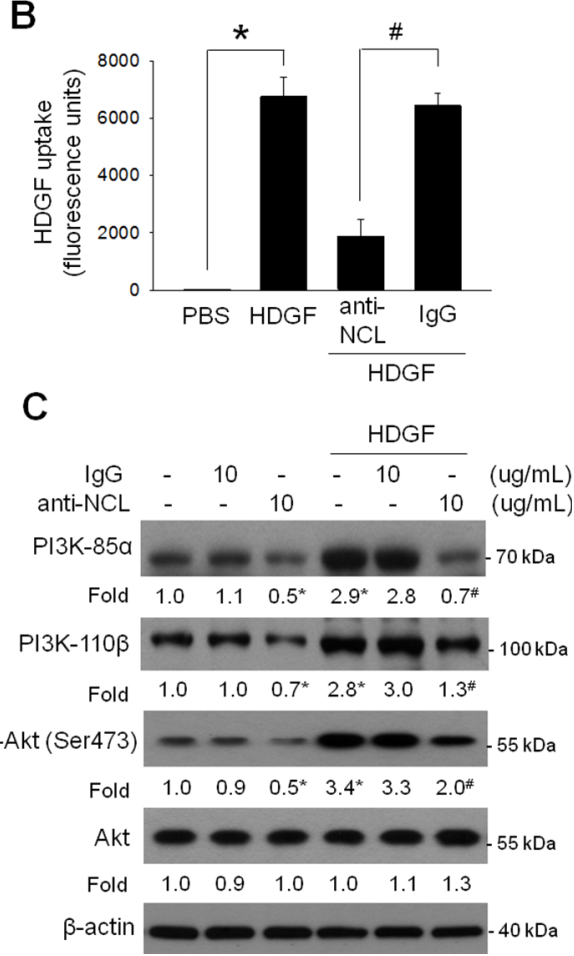

Figure 3: Effect of NCL blockade on HDGF uptake and HDGF-stimulated PI3K/Akt signaling of hepatoma cells. A. Effect of NCL blockade on HDGF uptake in SK-Hep-1 cells. After treatment with HDGF (10 ng/mL) in the absence or presence of anti-NCL neutralizing antibodies $(10 \mu \mathrm{g} / \mathrm{mL})$ for 4 hours, HDGF staining of cells permeabilized by Triton X-100 was detected using an anti-6xHis antibody and examined by a confocal microscope. Bar, $20 \mu \mathrm{m}$. B. Effect of NCL blockade on HDGF uptake in SK-Hep-1 cells. After treatment with Alexa Fluor 488 dye-labeled HDGF $(100 \mathrm{ng} / \mathrm{mL})$ in the absence or presence of anti-NCL neutralizing antibodies $(10 \mu \mathrm{g} / \mathrm{mL})$ for 4 hours, the amount of fluorescently-labeled HDGF was examined by a spectrofluorometer. ${ }^{*} P<0.05$. ${ }^{*} P<0.05$. C. Effect of NCL blockade on HDGF-stimulated PI3K/Akt signaling of SK-Hep-1 cells. After treatment with HDGF (10 ng/ml) for $24 \mathrm{hours}$, the protein levels of PI3K-85 $\alpha$, PI3K-110 $\beta$, p-Akt and Akt were assessed by immunoblot analysis. The data are presented as the mean $\pm \mathrm{SD}$ as percentages of the control. ${ }^{*} P<0.05$ versus control. ${ }^{*} P<0.05$ versus $10 \mathrm{ng} / \mathrm{mL}$ HDGF. 
patients [4]. However, the prognostic role of NCL has never been studied in HCC. Thus, we evaluated whether NCL overexpression is associated with tumour malignancy in HCC. By using a panel of hepatoma cells with different differentiation status, immunoblot analysis showed that the cellular NCL level exhibited an escalated trend from well-differentiated (HepG2 and Hep3B cells), intermediate-differentiated ( $\mathrm{J} 5$ and $\mathrm{Huh}-7$ cells), to poorly differentiated (Mahlavu and SK-Hep-1) hepatoma cells (Figure 4A). Interestingly, such trend of NCL upregulation was even more pronounced when analyzing the membrane NCL level among these hepatoma cells. Thus, these results implicated that NCL overexpression may be associated with loss of differentiation features in hepatoma cells. Subsequently, immunohistochemial analysis of NCL expression was performed using resected $\mathrm{HCC}$ samples $(n=147)$ to delineate the role of NCL in HCC progression. Using the scoring system for immunostaining intensities, the statistical analysis demonstrated that the NCL labeling index (LI) in the tumour tissues were higher than that in the non-tumour tissues $(P<0.001$; Figure 4B). Besides, the NCL LI increased as the tumour grades proceeded (Figure $4 \mathrm{C}$ ). To evaluate the clinical relevance of HDGF and NCL expression in HCC, we examined the expression patterns of HDGF and NCL in the surgical specimens of the earlystage HCC (TNM stage I or II) and the late-stage HCC (TNM stage III or IV). Immunofluorescence analysis revealed that the co-localization of HDGF and NCL in the late-stage HCC specimens was higher than that in the early-stage HCC specimens (Figure 4D). Statistical analyses further revealed the NCL LI was correlated positively with tumour grade $(P=0.010)$, vascular invasion $(P=0.034)$, and alpha-fetoprotein $(\alpha \mathrm{FP})$ level $(P=0.006$; Table 1$)$. There was a positive correlation between NCL LI and HDGF expression $(P=0.028)$. These results show that NCL overexpression is positively correlated with HCC progression.

\section{NCL is a novel prognostic factor for survival of HCC patients}

To evaluate the prognostic potential of NCL expression in $\mathrm{HCC}$, the patients were divided into 2 groups based on their NCL labeling intensities for survival analysis. Kaplan-Meier analysis showed that the NCL LI was inversely correlated with the overall survival rate of HCC patients after surgery ( $P=0.016$; Figure 4E).

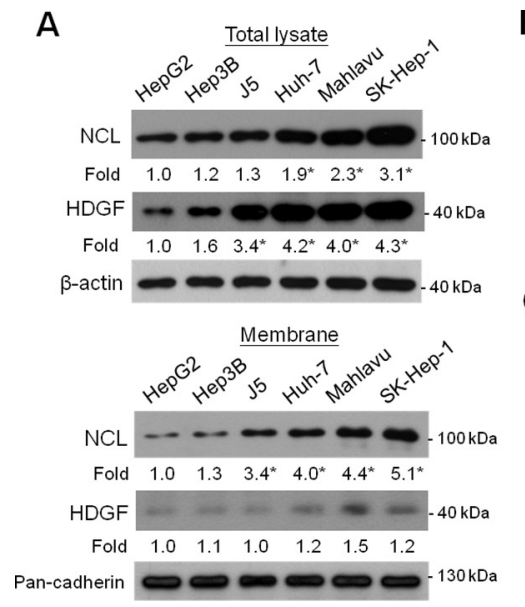

D
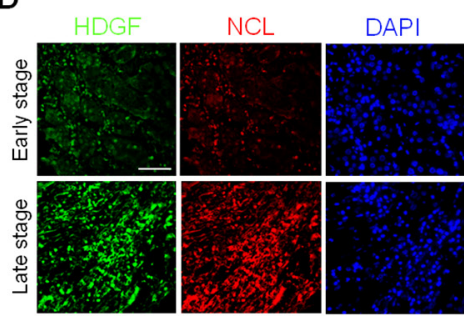

B

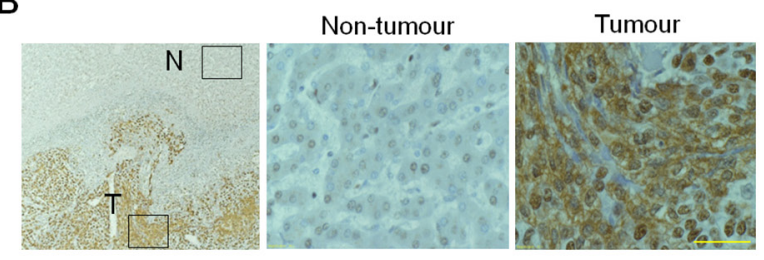

C
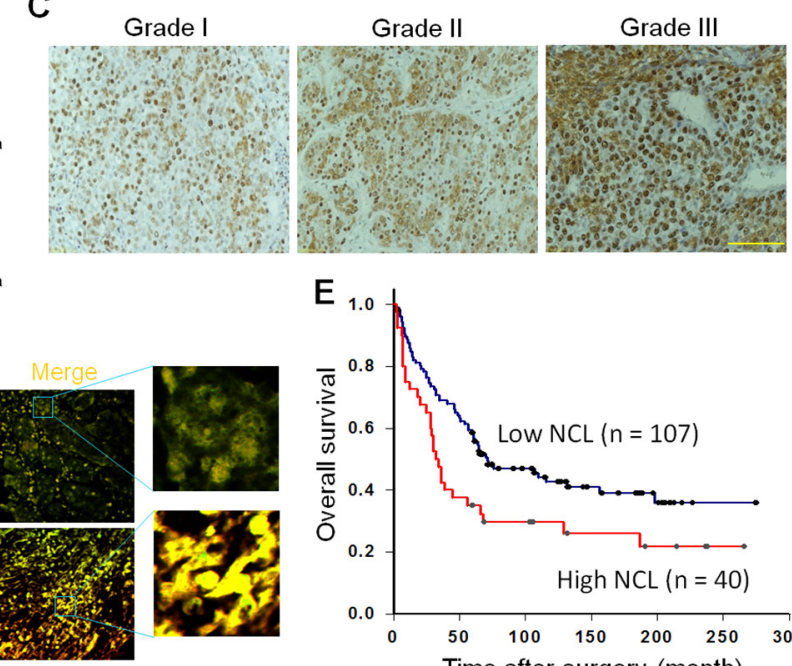

Grade II

$\mathrm{E}$
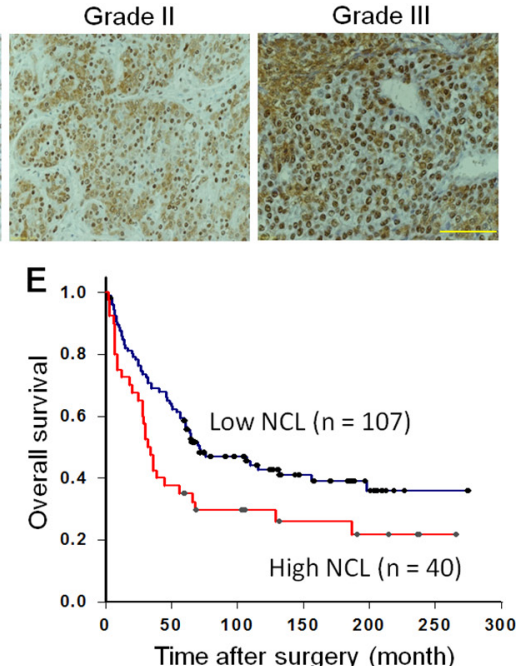

Figure 4: Expression of NCL in human HCC tissues and its association with tumour grade and the survival outcome. A. NCL and HDGF expression in human hepatoma cell lines. (Upper panel) Total extracts and (Lower panel) membrane extracts were isolated for immunoblot analyses of NCL and HDGF protein levels. The data are presented as the mean $\pm \mathrm{SD}$ as percentages of the control. $* P<0.05$ versus HepG2 cells. B. NCL expression in human HCC tissues. (Left) $40 \times$ magnification; (Middle) Non-tumour tissues. $400 \times$ magnification. (Right) Tumour tissues. $400 \times$ magnification. Bar, $100 \mu \mathrm{m}$. C. NCL expression in different grades of HCC tissues. $200 \times$ magnification. Bar, $200 \mu \mathrm{m}$. D. Immunofluorescence staining of HDGF (green) and NCL (red) in the different stages of human HCC tissues. Bar, $200 \mu \mathrm{m}$. E. Kaplan-Meier analysis of the overall survival for HCC patients with different NCL expression levels. 
Table 1: Correlation between NCL and clinicopathologic parameters of HCCs

\begin{tabular}{|c|c|c|c|}
\hline Variant & Low $(n=107)$ & High $(n=40)$ & $p$ value \\
\hline Gender & & & $\operatorname{NS}(0.59)^{\alpha}$ \\
\hline Female $(n=30)$ & 23 & 7 & \\
\hline Male $(n=117)$ & 84 & 33 & \\
\hline Cirrhosis & & & $\operatorname{NS}(0.056)^{\alpha}$ \\
\hline With $(n=88)$ & 59 & 29 & \\
\hline Without $(n=59)$ & 48 & 11 & \\
\hline HBsAg & & & $\mathrm{NS}(0.59)^{\alpha}$ \\
\hline Positive $(n=102)$ & 74 & 28 & \\
\hline $\begin{array}{l}\text { Negative }(n=39) \\
\text { (missing 6) }\end{array}$ & 30 & 9 & \\
\hline Anti-HCV & & & $\operatorname{NS}(0.78)^{\alpha}$ \\
\hline Positive $(n=32)$ & 23 & 9 & \\
\hline $\begin{array}{l}\text { Negative }(n=109) \\
\text { (missing } 6)\end{array}$ & 81 & 28 & \\
\hline HCC grades & & & ${ }^{*} 0.010^{\alpha}$ \\
\hline Well $(n=35)$ & 32 & 3 & \\
\hline Moderate $(n=71)$ & 50 & 21 & \\
\hline Poor $(n=41)$ & 25 & 16 & \\
\hline Capsule & & & $\operatorname{NS}(0.81)^{\alpha}$ \\
\hline With $(n=82)$ & 61 & 21 & \\
\hline Without $(n=65)$ & 46 & 19 & \\
\hline Vascular invasion & & & ${ }^{*} 0.034^{\alpha}$ \\
\hline Without $(n=73)$ & 59 & 14 & \\
\hline With $(n=74)$ & 48 & 26 & \\
\hline Tumour numbers & & & $\operatorname{NS}(0.40)^{\alpha}$ \\
\hline Solitary $(n=110)$ & 82 & 28 & \\
\hline Multi $(\geq 2)(n=37)$ & 25 & 12 & \\
\hline Age & $53.8 \pm 13.5$ & $55.2 \pm 12.8$ & NS $(0.59)^{\beta}$ \\
\hline Tumour size (cm) & $6.87 \pm 4.21$ & $5.65 \pm 3.14$ & NS $(0.09)^{\beta}$ \\
\hline$\alpha F P(n g / m L)$ & $2712 \pm 7191$ & $3404 \pm 11329$ & ${ }^{*} 0.006^{\gamma}$ \\
\hline
\end{tabular}

${ }^{*}$ Statistically significant $(p<0.05)$; ${ }^{\alpha}$ Chi-Square test, ${ }^{\beta}$ Student $t$ test, ${ }^{\gamma}$ Mann-Whitney $U$ Test. NS: not significant.

The patients with a strong NCL LI had low survival rates compared with the patients with a weak NCL LI (Figure 4E). However, NCL was not a significant prognostic marker for the disease-free survival of HCC patients $(P=0.078)$.

Univariate analysis in the Cox proportional hazard model revealed that NCL expression, serum $\alpha$ FP levels, tumour capsule, tumour size, vascular invasion and grade were independent variables to predict the overall survival $(P<0.05$; Table 2$)$. Notably, although not related to disease-free survival, multivariate analysis revealed that the high NCL expression in HCC could predict shorter patient's survival after resection and serve as an independent prognostic factor $(P<0.05$; Table 2$)$. These results show that NCL provides the prognostic potential for the survival outcome in HCC patients. 
Table 2: Correlation of clinicopathologic factors and overall survival of HCC patients

\begin{tabular}{|c|c|c|c|c|c|c|}
\hline & \multicolumn{3}{|c|}{ Univariate } & \multicolumn{3}{|c|}{ Multivariate } \\
\hline & Risk & $95 \% \mathrm{CI}$ & $\boldsymbol{P}$ & Risk & $95 \% \mathrm{CI}$ & $P$ \\
\hline \multicolumn{7}{|l|}{ Biomarkers } \\
\hline Nucleolin & 1.30 & $1.04-1.62$ & 0.018 & 1.32 & $1.06-1.66$ & 0.013 \\
\hline \multicolumn{7}{|l|}{ Clinical parameters } \\
\hline Age & 0.90 & $0.59-1.38$ & NS & - & - & - \\
\hline Gender & 1.32 & $0.78-2.23$ & NS & - & - & - \\
\hline$\alpha \mathrm{FP}$ & 1.68 & $1.11-2.55$ & 0.013 & - & - & NS (0.11) \\
\hline $\mathrm{HBV}$ & 1.36 & $0.84-2.20$ & NS & - & - & - \\
\hline $\mathrm{HCV}$ & 0.79 & $0.48-1.30$ & NS & - & - & - \\
\hline Viremia (B or C) & 2.87 & $1.13-4.89$ & 0.021 & - & - & NS $(0.35)$ \\
\hline Cirrhosis & 1.53 & $1.00-2.36$ & 0.050 & - & - & NS $(0.28)$ \\
\hline \multicolumn{7}{|c|}{ Pathologic parameters } \\
\hline Tumour capsule & 0.46 & $0.30-0.70$ & $<0.001$ & 0.52 & $0.33-0.83$ & 0.006 \\
\hline Tumour size & 1.95 & $1.28-2.95$ & 0.002 & - & - & NS (0.54) \\
\hline Tumour number & 1.34 & $0.85-2.12$ & NS & - & - & - \\
\hline Vascular invasion & 3.68 & $2.38-5.69$ & $<0.001$ & 2.72 & $1.71-4.32$ & $<0.001$ \\
\hline Grade & 1.56 & $1.17-2.08$ & 0.002 & - & - & NS (0.16) \\
\hline
\end{tabular}

Nucleolin, low or high; Age, $\geq 60$ or $<60$ years; Gender, male or female; serum $\alpha$-FP, $\geq 400$ or $<400$; HBV+, with or without; $\mathrm{HCV}+$, with or without; Cirrhosis, with or without; Tumour capsulation, with or without; Tumour size, $\geq 5$ or $<5 \mathrm{~cm}$; Tumour number, solitary or $\geq 2$; Grades, I + II or III + IV; Pathologic stages, I + II or III + IV. NS: not significant.

\section{NCL overexpression elicits HDGF upregulation and promotes the oncogenic behaviours via PI3K/Akt siganling in hepatoma cells}

We then investigated whether the cellular NCL level affected the oncogenic behaviours of hepatoma cells. Ectopic NCL overexpression using expression vector encoding NCL fused with green fluorescent protein (NCL-GFP) increased the cellular NCL protein level in SK-Hep-1 cells by approximately 3.3 -fold over the control (Figure 5A). Moreover, the NCL-transfected hepatoma cells exhibited significantly enhanced tumorigenicity of hepatoma cells including proliferation, invasiveness and anchorage-independent growth (Figure 5B-5D). Since $\mathrm{PI} 3 \mathrm{~K} / \mathrm{Akt}$ is the downstream effector of HDGF, we investigated whether NCL overexpression influenced the HDGF/Akt signaling in hepatoma cells. Immunoblot analysis showed that NCL overexpression significantly increased the HDGF protein level and stimulated the Akt phosphorylation in hepatoma cells (Figure 5E). Thus, NCL overexpression elicits HDGF upregulation and promotes the malignancy of hepatoma cells.
Similarly, NCL overexpression also enhanced the oncogenic behaviors in another hepatoma HepG2 cells (Supplementary Figure 2).

To confirm the role of PI3K/Akt signaling in HDGF/ NCL-induced tumorigenicity, a pharmaceutical PI3K inhibitor, LY2940002, was used. It was found LY2940002 application significantly suppressed the HDGF- or NCLstimulated invasion and colonies formation in hepatoma cells (Figure 6A-6B). Above all, LY2940002 treatment potently abolished the compounding effect of HDGF supply and NCL overexpression on oncogenic behaviors of hepatoma cells.

\section{NCL knockdown attenuates the basal and HDGF-stimulated oncogenic behaviours and PI3K/Akt pathway in hepatoma cells}

Subsequently, we evaluated the effect of NCL knockdown on the oncogenic behaviours of hepatoma cells using small interfering RNA (siRNA). Immunofluorescence and immunoblot analyses validated the efficacy of NCL siRNA in depleting NCL level in 
A

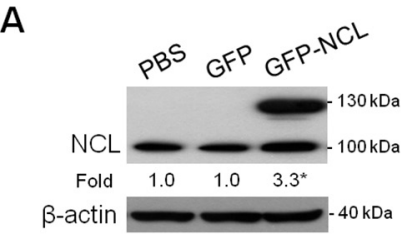

B

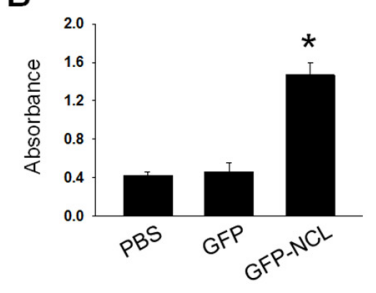

C

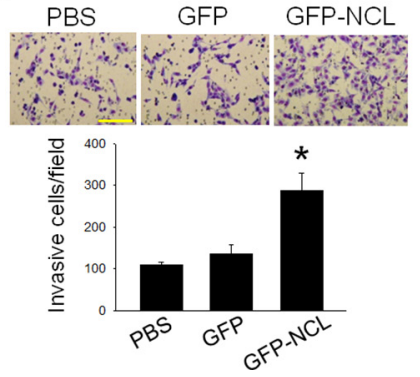

D
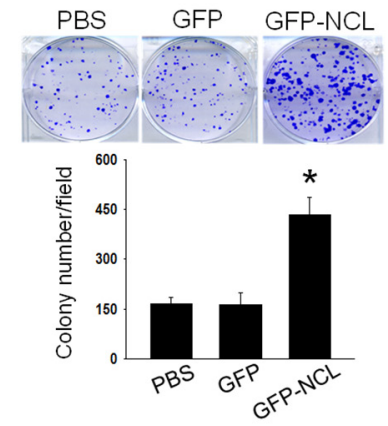

$\mathrm{E}$

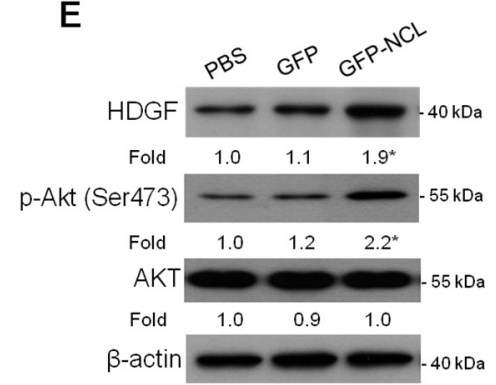

Figure 5: Influence of NCL overexpression on the oncogenic behaviors and HDGF/Akt signaling in hepatoma cells. After transfection with pEGFP-C1 vector encoding NCL fused with green fluorescent protein (NCL-GFP) for 48 hours, cells were harvested for subsequent analysis. A. Effect of NCL-GFP transfection on NCL expression in SK-Hep-1 cells. The protein levels of NCL were assessed by immunoblot assay. B. Effect of NCL-GFP transfection on proliferation of SK-Hep-1 cells. Cell proliferation was assessed by MTT assay. C. Effect of NCL-GFP transfection on invasion of SK-Hep-1 cells. The invasion capability was assessed by Boyden chamber assay. Bar, $250 \mu \mathrm{m}$. D. Effect of NCL-GFP transfection on anchorage-independent growth of SK-Hep-1 cells. The colony-forming capability was determined by crystal violet and counted. E. Effect of NCL overexpression on the protein expressions of HDGF and p-Akt in SK-Hep-1 cells. The protein levels of HDGF, p-AKT and AKT were assessed by immunoblot assay. The data are presented as the mean \pm SD as percentages of the control. $* P<0.05$ versus control.

hepatoma cells (Figure 7A). Moreover, NCL knockdown significantly attenuated the basal and HDGF-stimulated proliferation, invasiveness and anchorage-independent growth of hepatoma cells (Figure 7B-7D). Immunoblot analysis further showed that NCL knockdown potently inhibited the basal and HDGF-stimulated PI3K expression and Akt phosphorylation in hepatoma cells (Figure 7E). Similar results were observed using another hepatoma Huh-7 cells (data not shown), or another NCL RNAi (Supplementary Figure 3). Together, these findings indicate NCL knockdown attenuates the basal and HDGFstimulated oncogenic behaviours and PI3K/Akt pathway in hepatoma cells. In summary, we herewith proposed the hypothetical model for HDGF-induced NCL membrane targeting and accumulation, which activates PI3K/Akt signaling to promote liver carcinogenesis (Figure 8).

\section{DISCUSSION}

The present study employed various approaches including affinity chromatography, LC-MASS peptide identification, immunofluorescence analysis, co-IP and GST pull down assays to demonstrate HDGF directly binds to surface NCL and regulates the NCL membrane translocalization, NCL gene expression, $\mathrm{NCL} / \mathrm{PI} 3 \mathrm{~K} /$ Akt pathway and oncogenic behaviours in hepatoma cells. The histological studies using human HCC samples unveil the positive correlation of NCL expression with tumour grade, vascular invasion and HDGF expression in HCC patients. Moreover, NCL overexpression constitutes an independent prognostic factor in predicting the overall survival of HCC patients. Above all, NCL inactivation suppresses the HDGF-stimulated oncogenic behaviours and PI3K/Akt activities in hepatoma cells, implicating the potential of $\mathrm{NCL}$ as a novel therapeutic target for HCC. Collectively, these results provide the compelling evidence supporting NCL participates in liver carcinogenesis through transmitting HDGF signaling.

By demonstrating the binding of HDGF with NCL in plasma membrane, our results are in agreement with a recent study, in which the interaction and 


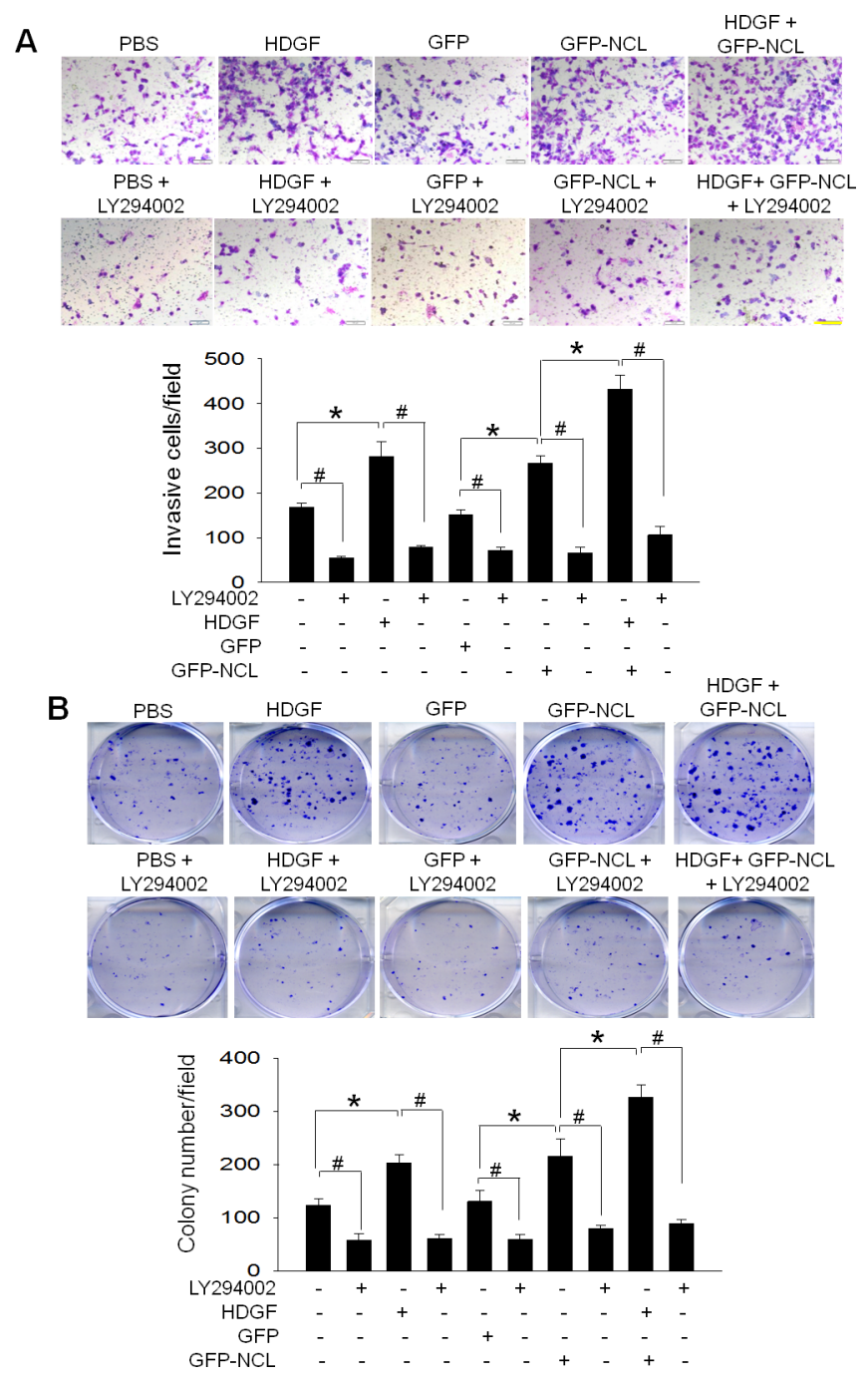

Figure 6: Effect of LY294002 on HDGF/NCL-stimulated the oncogenic behaviors in hepatoma cells. After treatment with HDGF $(10 \mathrm{ng} / \mathrm{mL})$ or/and transfection with pEGFP-C1 vector encoding NCL in the absence or presence of LY294002 $(10 \mu \mathrm{M})$ for the indicated times, SK-Hep-1 cells were harvested for subsequent analysis. A. Effect of LY294002 on HDGF/NCL-stimulated the invasion of SK-Hep-1 cells. The invasion capability was assessed by Boyden chamber assay. Bar, $250 \mu \mathrm{m}$. B. Effect of LY294002 on HDGF/NCLstimulated the anchorage-independent growth of SK-Hep-1 cells. The colony-forming capability was determined by crystal violet and counted. The data are presented as the mean $\pm \mathrm{SD}$ as percentages of the control. ${ }^{*} P<0.05$. ${ }^{*} P<0.05$.

co-localization between HDGF and NCL takes place in the ribonucleoprotein complex [19]. Nevertheless, the present study has further delineated that HDGF binds to the N-terminal domain of NCL through its heparin-binding HATH domain. This is also consistent with the previous study that the HATH domain (particularly Lys96 residue) is critical to the cellular uptake of HDGF [16]. By locating in the extracellular space, the N-terminal domain of NCL consists of high content of acidic residues and hence facilitates the binding with ligands rich in basic amino acids, such as midkine and heparan-binding domain of matrix proteins $[20,21]$. However, several fundamental issues regarding the interaction between HDGF and NCL remain to be solved. For example, the binding affinity (i.e., the dissociation constant) between NCL and HDGF is not determined yet.
NCL, a multiple-function protein shuttles between the cell surface and the nucleus, is involved in RNA biogenesis, cell proliferation, differentiation, adhesion, mitogenesis and angiogenesis [22, 23]. Interestingly, surface NCL is also a receptor for various molecules including cytokines (like midkine and pleiotrophin) $[21,24]$, vascular-targeting factors (endostatin and tumour-homing peptide F3) $[25,26]$ and some glycosaminoglycans [27]. Because both HDGF and NCL bind to heparin, it seems possible that HDGF may interact with NCL in a glycoprotein-dependent manner. However, besides proteoglycan, additional molecules may participate in the formation of surface HDGF-NCL signaling complex because several distinct proteins other than NCL are present in elutes from HDGF affinity column chromatography (data not shown). It is hypothesized that 
A
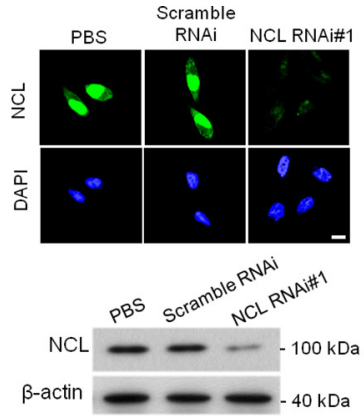

B

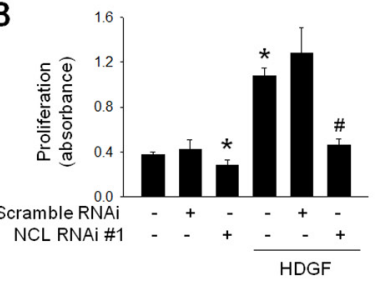

C
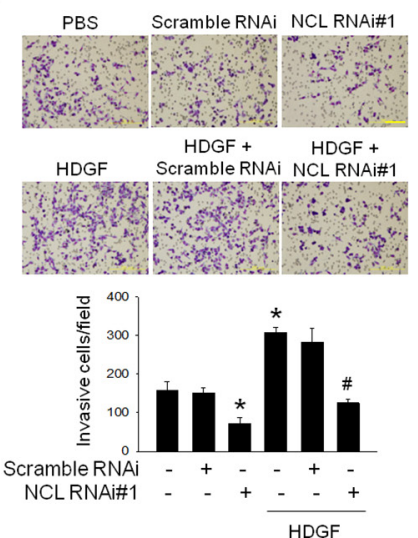

D
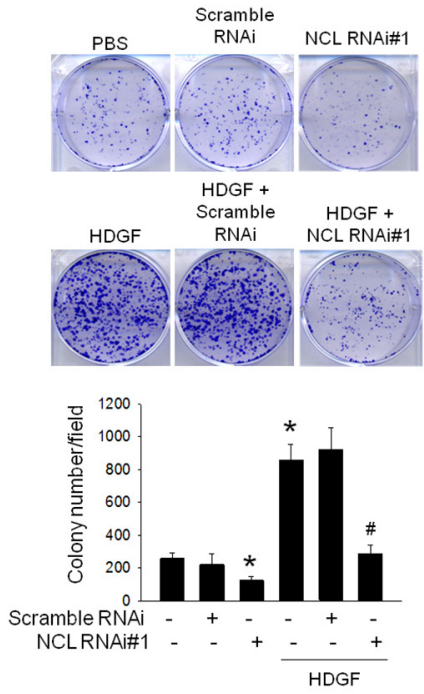

$\mathrm{E}$

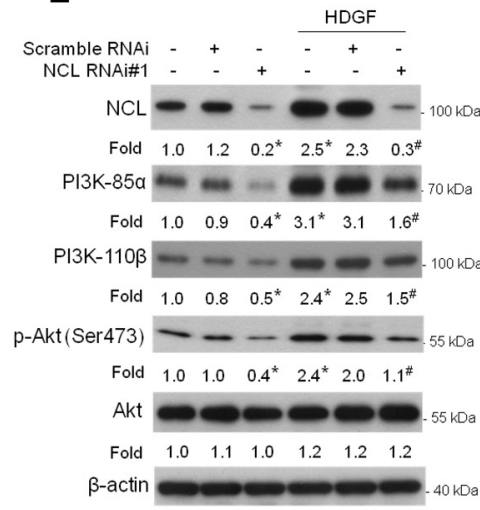

Figure 7: Effect of NCL knockdown on the basal and HDGF-stimulated oncogenic behaviours and PI3K/Akt signaling of hepatoma cells. After treatment with HDGF $(10 \mathrm{ng} / \mathrm{mL})$ in the absence or presence of NCL siRNA\#1 $(0.5 \mu \mathrm{g})$ for the indicated times, cells were harvested for the subsequent analysis. A. Effect of NCL siRNA\#1 on NCL protein level in SK-Hep-1 cells. After transfection for 72 hours, NCL expression was detected by (Upper panel) immunofluorescence assay and (Lower panel) immunoblot analysis using an anti-NCL antibody. Bar, $20 \mu \mathrm{m}$. B. Effect of NCL siRNA\#1 on proliferation of SK-Hep-1 cells. After treatment with HDGF for 24 hours, cell proliferation was assessed by MTT assay. C. Effect of NCL siRNA\#1 on invasiveness of SK-Hep-1 cells. After treatment with HDGF for 24 hours, the invasion capability was assessed by Boyden chamber assay. Bar, $250 \mu \mathrm{m}$. D. Effect of NCL siRNA\#1 on anchorageindependent growth of SK-Hep-1 cells. After treatment with HDGF for 10 days, the colony-forming capability was detected by crystal violet solution and counted. E. Effect of NCL siRNA\#1 on PI3K/Akt signaling of SK-Hep-1 cells. After treatment with HDGF for 24 hours, the protein levels of NCL, PI3K-85 $\alpha$, PI3K-110 $\beta$, p-Akt and Akt were assessed by immunoblot assay. The data are presented as the mean \pm SD as percentages of the control. ${ }^{*} P<0.05$ versus control. ${ }^{~} P<0.05$ versus $10 \mathrm{ng} / \mathrm{mL}$ HDGF.

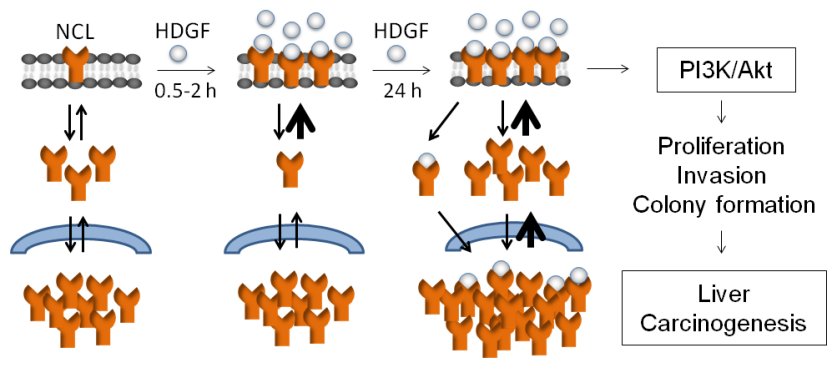

Figure 8: Hypothetical model for HDGF-induced NCL membrane trafficking from cytoplasm (in 0.5-2 hours), NCL upregulation (in 24 hours), activation of PI3K/Akt pathway and oncogenic behaviours of hepatoma cells, which ultimately contributes to liver carcinogenesis. 
NCL may serve as the high-affinity receptor for HDGF whereas the other co-receptor proteins may confer the specificity for HDGF recognition in the oncogenic HDGF/ NCL signaling axis. Studies are currently undergoing to characterize the existence and functions of these HDGFbinding membrane proteins.

The identification of NCL as a receptor for HDGF brings important insights on the signaling pathway of HDGF. NCL has been demonstrated to bind directly to PI3K complex in lymphoma cells during CD21 activation [28]. Thus, HDGF may directly induce Akt activation in hepatoma cells through NCL. Alternatively, it has been reported surface NCL is associated with other oncogenic receptors including ErbB and c-Met [29, 30]. Thus, in addition to direct PI3K/Akt activation, HDGF/NCL axis may also participate in liver carcinogenesis through interaction with other oncogenic pathways. Moreover, our studies unveiled that modulation of NCL expression could regulate HDGF expression in a feedback manner through as yet unidentified mechanism. Thus, the coordinate and reciprocal interaction between HDGF and NCL strongly advocates the important role of HDGF/NCL signaling axis in liver carcinogenesis.

To our knowledge, the present study has presented the first evidence for the prognostic function of NCL that NCL expression is correlated with tumour progression and inversely associated with the survival outcome of HCC patients after surgery. NCL overexpression is observed in several types of cancer with high proliferative rates including melanoma and breast cancer [31, 32]. Recently, the prognostic role of NCL has been reported in pediatric intracranial ependymoma, cutaneous melanocytic lesions and gastric cancer tissues, in which nuclear NCL overexpression is associated with the tumour progression of pediatric ependymoma, melanoma and gastric cancer [33-35]. This is in accordance with the pro-oncogenic function of NCL in our HCC study. Future studies are warranted to delineate whether NCL may serve a novel diagnostic marker for liver diseases such as hepatitis and liver fibrosis/cirrhosis, which proceed prior to the development of HCC.

Recent evidence advocates that surface NCL may facilitate as a novel molecular target for cancer therapy. At present, there are several anti-neoplastic agents targeting at cell surface NCL including AS1411, an nucleic acid-based aptamer that binds to cell surface NCL [36], and HB-19 pseudopeptide, which acts directly on the C-terminal domain of NCL [22]. By unveiling NCL serves as a HDGF receptor, the present study echoes such view that surface NCL may constitute a therapeutic target for liver cancer. Our study has further demonstrated the antitumor efficacy of NCL inactivation via knockdown and antibodies neutralization in suppressing the tumorigenicity of hepatoma cells even in the presence of excessive HDGF. Further studies using the pre-clinical HCC animal models are required to fully optimize and appreciate the therapeutic potential of NCL-targeting modalities for HCC.
In conclusion, this study provides the first evidence that NCL is a HDGF receptor and mediates the HDGFstimulated oncogenic behaviours and PI3K/Akt pathway. NCL expression is positively correlated with tumour grade, vascular invasion and shorter survival outcome in HCC patients. Therefore, HDGF/NCL axis participates in liver carcinogenesis and facilitates a novel diagnostic and therapeutic target for HCC.

\section{MATERIALS AND METHODS}

\section{Cell cultures}

HepG2 and Hep3B cells were cultured in minimum essential medium (MEM), Mahlavu and SK-Hep-1 cells were cultured in Dulbecco's modified Eagle's medium (DMEM). These four cell lines were from the American Type Culture Collection (Manassas, VA). J5 and Huh-7 were cultured in DMEM and purchased from the Food Industry Research and Development Institute (Hsinchu, Taiwan). Both MEM and DMEM supplemented with $10 \%$ fetal calf serum (FCS), $100 \mathrm{IU} / \mathrm{mL}$ penicillin, $100 \mu \mathrm{g} / \mathrm{mL}$ streptomycin, and $2 \mathrm{mM} \mathrm{L}$-glutamine in $5 \%$ $\mathrm{CO}_{2}$ at $37^{\circ} \mathrm{C}$.

\section{Isolation of HDGF-binding membrane proteins}

SK-Hep-1 cells were washed twice with cold PBS and collected with EDTA. After centrifugation, the pellet was re-suspended in $1 \mathrm{~mL}$ ice-cold hypotonic buffer (10 mM HEPES pH 7.9, $0.5 \mathrm{mM}$ dithiothreitol, protease inhibitors: $0.5 \mathrm{mM}$ phenylmethylsulfonyl fluoride, aprotinin, pepstatin, leupeptin $(10 \mu \mathrm{g} / \mathrm{ml}$ each); and phosphatase inhibitors: $50 \mathrm{mM} \mathrm{NaF}, 30 \mathrm{mM}$ $\beta$-glycerophosphate, $1 \mathrm{mM} \mathrm{Na} \mathrm{VO}_{4}$, and $20 \mathrm{mM}$ $\rho$-nitrophenyl phosphate). The cells were disrupted with a tight-fitting Dounce homogenizer. The homogenate was checked under Olympus phase contrast microscope and no intact cell could be observed. The homogenate was centrifuged to remove the nuclei and mitochondria at $8000 \mathrm{~g}$ for 10 minutes. The supernatant was centrifuged at $100000 \mathrm{~g}$ for 30 minutes. The membrane fraction, obtained as the pellet, was dissolved in $200 \mu \mathrm{L}$ ice-cold hypotonic buffer containing $1 \%$ Triton X-100 for 1 hour.

\section{Identification of HDGF-binding membrane proteins}

The affinity columns were prepared by incubation of recombinant C140 or HDGF (5 mg) with $2 \mathrm{~mL}$ Ni-NTA agarose (50\% in PBS; Qiagen, Hilden, Germany). The membrane proteins $(5 \mathrm{mg})$ were incubated with the affinity columns for 12 hours at $4{ }^{\circ} \mathrm{C}$, and unbound proteins were removed by washing with phosphate buffered saline (PBS). The fractions were collected by 
elute buffers (20 mM Tris-HCl, pH 7.9, $500 \mathrm{mM} \mathrm{NaCl}$, $200 \mathrm{mM}$ imidazole). The elutes from various affinity columns were separated by electrophoresis on $10 \%$ SDSpolyacrylamide gel and subjected to silver staining. The silver-stained gel pieces were excised for in-gel digestion. The remaining peptides from the gel piece were further analyzed by Nano-HPLC-MS/MS (Thermo Finnigan, San Jose, CA). The resulting MS/MS spectra were searched against NCBI database using Mascot search engine (http://www.matrixscience.com, Matrix Science Ltd., UK). Proteins identified with a $P$ value less than 0.05 were considered candidate hits. Information of the identified proteins was referred to the Human Protein Reference Database (http://www.hprd.org).

\section{HDGF proteins, HDGF antibodies, adenovirus vectors, and other reagents}

Recombinant HDGF proteins and anti-HDGF antibodies were generated as previously described [4]. The human HDGF cDNA was amplified from a human fetal brain cDNA library (Stratagene, La Jolla, CA) using the polymerase chain reaction (PCR). The PCR primers used to clone the human HDGF cDNA were designed based on the HDGF sequence in the GenBank database. All HDGF fragments were amplified by PCR using primers as follows: HDGF, 5'-CCGCATATGTCGCGATCCAACC GGCAGAAG-3' (forward) and 5'-CGCGGATCCCTACAGGCTCTCATGATC-3' (reverse); 5'-CGCCATATGCAGTCCTCCCAGAAAAAG-3' (forward) C140, 5'-CGCGGATCCCTACAGGCTCTCATGATC-3'

(reverse). After the DNA sequencing analysis, the PCRamplified cDNA of all HDGF fragments was subcloned into the NdeI and BamHI sites of the pET15b vector (Novagen, Madison, WI) and transformed into BL21 cells (DE3, pLysS; Novagen). All 6xHistidine-tagged recombinant proteins were purified on an NTA-agarose affinity column (Qiagen, Hilden, Germany), desalted on a G25 Sephadex column (Amersham Pharmacia, Little Chalfont, United Kingdom), and passed through a Detoxi-Gel column (Pierce Biotechnology, Rockford, IL) to minimize contamination by endotoxins. Purity and correct molecular weight of the recombinant proteins were examined by coomassie blue staining of SDSPAGE gels and immunoblot analysis using an anti-6xHis antibody (Santa Cruz, CA). Rabbit anti-HDGF pAbs were generated by the periodic injection of recombinant HDGF into rabbits. The serum was collected from immunized animals and analyzed using immunoblot analysis.

The recombinant adenoviruses containing green fluorescent protein (Ad-GFP), HDGF cDNA (Ad-HDGF), and HDGF small-interfering RNA (Ad-HDGF RNAi) were generated as previously described [12].
FCS, DMEM, MEM and 1,1'-dioctadecyl-3,3,3', 3'-tetramethylindocarbocyanine (DiI) dye were obtained from Invitrogen Corp. (Carlsbad, CA). Other chemicals were obtained from Sigma-Aldrich Co. (St. Louis, MO).

\section{Co-immunoprecipitation assay}

Co-immunoprecipitation assay was performed as previously described $[37,38]$. The membrane proteins $(500 \mu \mathrm{g} / \mathrm{mL})$ were incubated with HDGF protein $(500 \mathrm{ng} / \mathrm{mL})$ for 4 hours at $4^{\circ} \mathrm{C}$, and then immunoprecipitated using an anti-NCL antibody (SigmaAldrich) for 1 hour at $4^{\circ} \mathrm{C}$. Immunocomplexes were collected on $15 \mu \mathrm{L}$ protein A/G beads (Calbiochem, San Diego, CA). The precipitated proteins were washed three times with $1 \%$ NP-40 lysis buffer $(20 \mathrm{mM}$ Tris- $\mathrm{HCl}$, $150 \mathrm{mM} \mathrm{NaCl}, 1 \mathrm{mM}$ EDTA, $1 \mathrm{mM}$ dithiothreitol, 1\% Nonidet P-40, 10\% glycerol, $1 \mathrm{mM}$ sodium orthovanadate, and one protease inhibitor mixture tablet), boiled for 5 minutes in SDS sample buffer, and subjected to immunoblot analysis with anti-HDGF, anti-6xHis and anti-NCL antibodies.

\section{GST pull down assay}

GST pull down assay was assessed as previously described [39]. The nucleolin (NCL) constructs including NCL1 (residues 1-284), NCL2 (residues 285-645), and NCL3 (residues 646-707) were generated from a human NCL cDNA clone $[21,40]$ and subcloned into the NdeI and BamHI sites of the $\mathrm{pET} 15 \mathrm{~b}$ vector (Novagen, Madison, WI) and transformed into BL21 cells (DE3, pLysS; Novagen). All recombinant NCL proteins were generated and purified by means of their N-terminal 6xHistidine tag.

The expression plasmid pGST-HDGF vector was constructed for production of GST-fused HDGF. After transformation, E. coli BL21(DE3) cells carrying GST expression vectors were cultured in $3 \mathrm{~mL}$ of LB media at $37^{\circ} \mathrm{C}$ to the mid-log phase. Isopropylthio- $\beta$-D-galactoside (IPTG) was then added to a final concentration of $1 \mathrm{mM}$ to induce the expression of GST fusion proteins. After culturing for 3 hours, BL21 cells were pelleted by centrifugation and suspended in $100 \mu \mathrm{L}$ of a lysis buffer, B-Per (Pierce), containing $10 \mu \mathrm{L}$ of leupeptin, aprotinin, and 4-(2-aminoethyl)-benzenesulfonyl fluoride. The suspension was centrifuged again at $10000 \mathrm{rpm}$ for 5 minutes at $4^{\circ} \mathrm{C}$. Glutathione-Sepharose 4B beads $(20 \mu \mathrm{L})$ (GE Healthcare, Piscataway, NJ) were added to the supernatant and the mixture was incubated under shaking for 1 hour at $4^{\circ} \mathrm{C}$. The beads were washed 3 times with NETN buffer $(20 \mathrm{mM}$ Tris-HCl, pH 8.0, $100 \mathrm{mM} \mathrm{NaCl}, 1 \mathrm{mM}$ EDTA, 0.5\% NonidetP-40). After washing, the beads were added to the lysate $(300 \mu \mathrm{L})$ prepared from $E$. coli lysate containing 6xHistidine-tagged NCL proteins. The reaction mixture was incubated on ice for 1 hour to allow binding between GST-HDGF proteins and 6xHistidine-tagged NCL proteins. 
The beads were subsequently washed with NETN buffer. An equal volume of $2 x$ electrophoresis sample buffer was added to the beads, proteins were extracted from the beads by heating at $95^{\circ} \mathrm{C}$ for 5 minutes. Proteins were finally analyzed by SDS-PAGE and immunoblot analysis.

\section{Immunofluorescence analysis}

Immunofluorescence staining was performed as previously described [17]. Cells were fixed with either $4 \%$ paraformaldehyde for monitoring the cell surface NCL staining and $4 \%$ paraformaldehyde $/ 0.2 \%$ Triton X-100 for monitoring the intracellular NCL staining. Fixed cells were incubated with the antibodies against HDGF (1:1000 dilution), 6xHis (1:100 dilution; Santa Cruz, CA) and NCL (1:1000 dilution; Sigma-Aldrich). The plasma membrane were identified using the well-characterized fluorescent marker DiI. The nuclei were counterstained with 4',6-diamidino-2-phenylindole (DAPI). Confocal double-immunostaining images were captured with a confocal microscope (ZEISS LSM PASCAL, ZEISS, German). The WCIF-Image J software (National Institutes of Health, Bethesda, MD) was used for measurement and quantification analysis of co-localizing images.

\section{HDGF uptake assay}

6xHistidine-tagged recombinant HDGF was labeled with Alexa Fluor488 reactive dye and purified according to the manufacturer's instructions (Molecular Probes, Invitrogen). The cells were incubated in DMEM supplemented with Alexa Fluor488 dye-labeled HDGF $(100 \mathrm{ng} / \mathrm{ml})$ in the absence or presence of an anti-NCL neutralizing antibody $(10 \mu \mathrm{g} / \mathrm{mL}$; Santa Cruz, CA) for 4 hours. Subsequently, SK-Hep-1 cells were washed with PBS and lysised with cell lysis buffer (50 mM Tris, $150 \mathrm{mM} \mathrm{NaCl}, 1 \mathrm{mM}$ Na-orthovanadae, $1 \mathrm{mM}$ EDTA). The fluorescence of Alexa Fluor488 dye-labeled HDGF was measured using a spectrofluorometer (FLUOstar galaxy, BMG Labtech GmbH, Offenburg, Germany) with excitation set at $485 \mathrm{~nm}$ and emission set at $520 \mathrm{~nm}$.

\section{Immunoblot analysis}

Immunoblot analysis was performed as previously described [11]. Ten $\mu \mathrm{g}$ of cell lysate was subjected to electrophoresis on 10\% SDS-PAGE. Primary antibodies were used to detect HDGF (1:10000 dilution), NCL (1:10000 dilution; Sigma-Aldrich), PI3K-85a (1:1000 dilution; Santa Cruz), PI3K-110ß (1:1000 dilution; Santa Cruz), p-AKT Ser473 (1:1000 dilution; Santa Cruz) and AKT (1:5000 dilution; Santa Cruz).

\section{Determination of NCL stability}

Protein stability assay was performed as previously described [17]. After incubation with HDGF
$(10 \mathrm{ng} / \mathrm{mL})$ for the indicated times, cells were treated with cycloheximide $(50 \mu \mathrm{g} / \mathrm{mL})$ for the various time intervals and subjected to immunoblot analysis to determine the half-life of NCL protein.

\section{Flow cytometry analysis of cell surface NCL level}

Flow cytometry analysis was performed as previously described [41]. Fixed cells were incubated with either anti-NCL antibodies (10 $\mu \mathrm{g} / \mathrm{mL}$; Santa Cruz) or controlIgG for 1 hour on ice, follow by adding an Alexa Fluor 488-conjugated secondary antibody (1:50 dilution; Molecular Probes, Eugene, Oregon). The antibodytreated cells were washed and re-suspended in $50 \mu \mathrm{L}$ PBS containing $2 \mu \mathrm{g} / \mathrm{mL}$ propidium iodide to distinguish between live and dead cells, and 10000 cells per sample were analyzed using a FACSCalibur flow cytometer (BD Biosciences, San Jose, CA) equipped with CellQuest software.

\section{Quantitative reverse transcription-polymerase chain reaction (qRT-PCR)}

One-twentieth of the complementary DNA generated was used as a template for real time PCR analysis. Amplification and detection was performed using a LightCycler DNA Master SYBR Green I kit (Roche Applied Science, Mannheim, Germany) in a LightCycler Detection System (Roche Applied Science). The PCR reaction was performed as follows: one cycle of $95^{\circ} \mathrm{C}$ for 10 minutes and 40 cycles of $95^{\circ} \mathrm{C}$ for 15 seconds, $60^{\circ} \mathrm{C}$ for 20 seconds and $72^{\circ} \mathrm{C}$ for 15 seconds. The primer sequences were as follows: $\beta$-actin, 5'-TCCTGTGGCATCCACGAAACT-3' (forward) and 5'-GAA GCATTTGCGGTGGACGAT-3' (reverse); NCL, 5'-AACCTCTCCTACAGTG CAACA-3' (forward) and 5'-CTGGCTTCTGGCATTAGGTG-3' (reverse).

\section{Resected HCC specimens}

A total of $147 \mathrm{HCC}$ paraffin specimens were collected by surgical resection at Department of Pathology at Kaohsiung Chang Gung Memorial Hospital from January 1987 to December 1998. The closing date of follow-up was 31 December 2006. All the HCC patients were diagnosed with resectable tumour(s) after liver biochemical test, and complete imaging studies including sonography, computed tomography, and/or angiography. The durations of follow-up were estimated in months. The survival of patients who died owing to HCCunrelated factors during the long periods of follow-up was estimated till the event and treated as censored data. Hepatitis markers, serum alpha-fetoprotein $(\alpha \mathrm{FP})$ levels, and other clinical parameters of HCC patients were also recognized. All the HCC specimens consisted of both the tumour and adjacent non-tumour parts. Tumour sizes were recorded as the largest diameter in the specimen. 
The background of the non-tumour part was characterized as cirrhotic or non-cirrhotic. The differentiated states of HCC were divided into three groups as well (grade I carcinoma of Edmondson-Steiner classification), moderate (grade II carcinoma of Edmondson-Steiner classification), and poor (grades III and IV carcinoma of Edmondson-Steiner classification). The pathologic stages of HCC were classified according to the staging system by the International Union against Cancer with a minor modification: stage I, encapsulated, without evidence of liver or vascular invasion; stage II, unencapsulated or capsulated and with liver invasion, but without vascular invasion; stage III, invasion of small vessels in the tumour capsule or focal invasion of portal vein branches close to the tumour; and stage IV, invasion of portal vein in the distal liver ( $1 \mathrm{~cm}$ away from the tumour capsule), branches of major portal vein, common bile duct, or perforation into visceral peritoneum. The experimental protocols were approved by the institutional review committee.

\section{Immunohistochemical analysis}

Immunohistochemical analysis of NCL expression in HCC samples was performed using primary antibodies against NCL (1:500 dilution; Sigma-Aldrich) and detected by colorimetric reaction using a HRP-linked polymer detection system (Biogenex; San Ramon, CA) with counterstaining by Gill's hematoxylin. The nuclear and cytoplasmic NCL staining in HCC and non-neoplastic counterpart were graded, respectively. The slides were scanned with Pannoramic Scan (3D HISTECH, Budapest, Hungary) for grading of NCL nuclear staining. Briefly, three representative areas in either HCC or nonneoplastic tissue were analyzed with ImmunoScreener and NuclearQuant (3D HISTECH) and graded as none or weak, intermediate and strong staining after software analysis. Finally, HCC tissues with weak or intermediate NCL staining were combined as low group $(n=107)$ and compared with strong NCL staining (labeled as high; $n=40$ ) for subsequent correlation between the NCL LI and clinicopathological parameters of HCC, as well as Cox hazard regression model.

\section{NCL RNA interference}

NCL gene silencing was achieved though transfection with NCL siRNA using the siRNA transfection reagent according to the manufacturer's instructions (Santa Cruz and Life Technologies). The sequences of the pool in NCL siRNA\#1 were as the following: sense 1: CUACGGCUUUCAAUCUCUUtt and antisense 1: AAGAGAUU GAAAGCCGUAGtt; sense 2: UGUUGUGGAUGUCAGAAUUtt and antisense 2: AAUUCUGACAUCCACAACAtt; sense 3: CCUGUGGUCUCCUUGGAAAtt and antisense 3: UUUCCAAGGAGACCACAGGtt, and sense
4: UGAUAGAGCUAA CCCUUAUtt and antisense 4: AUAAGGGUUAGCUCUAUCAtt (Santa Cruz). The sequences of NCL siRNA\#2 were as the following: sense, 5'-GCGGAGAUCAGAUUAGUCAtt-3' and antisense, 5'-UGACUAAUCUG AUCUCCGCag-3' (Life Technologies, Austin, TX). For each transfection, $0.5 \mu \mathrm{g}$ of NCL siRNA or scramble siRNA with $4 \mu \mathrm{L}$ of siRNA transfection reagent was added to siRNA transfection media. The siRNA transfection media was overlaid onto the cells for 6 hours. The media was then aspirated and the cells were maintained in DMEM supplemented with FCS for the further study. After transfection for 48 hours, hepatoma cells were subjected to various functional assays in the absence or presence of HDGF $(10 \mathrm{ng} / \mathrm{ml})$ for indicated time interval.

\section{Cell proliferation assay}

The cells were incubated in DMEM supplemented with HDGF $(10 \mathrm{ng} / \mathrm{mL})$ or the indicated reagents. After 20 hours incubation, the media was added 3-[4,5-dimethylthiazol-2-yl]-2,5-diphenyl-tetrazolium bromide (MTT) solution for additional 4 hours. Subsequently, cells were lysised with isopropanol supplemented with $50 \mathrm{mM}$ hydrochloride, and the absorbance at $570 \mathrm{~nm}$ was measured.

\section{Cell invasion assay}

The cell invasion was measured using the transwell assay in a Boyden chamber (48-well plate) using a polycarbonate filter ( $8 \mu \mathrm{m}$ pore size; Nucleopore, Costar, Cambridge, MA). The polycarbonate filter was coated with Matrigel ( $2 \mathrm{mg} / \mathrm{mL}$; BD Biosciences) at $4^{\circ} \mathrm{C}$ for 1 hour and placed on the lower compartment of a 48 -well plate with DMEM containing $10 \%$ FCS as a chemoattractant. The cells $\left(1 \times 10^{5}\right.$ cells $\left./ \mathrm{mL}\right)$ supplemented in DMEM containing HDGF $(10 \mathrm{ng} / \mathrm{mL})$ or the indicated reagents were seeded in the wells $(50 \mu \mathrm{L} /$ well $)$ of the upper compartment. After 24-hours of incubation, the invading cells on the lower surface of the polycarbonate filter were stained with $0.5 \%$ crystal violet and observed by microscopy. The number of invading cells was counted from at least four high-power fields $(200 \times$ magnification $)$ per assay, and the data are presented as the averages of triplicate experiments.

\section{Colony formation assay}

Flat colony formation assay was performed as previously described [5]. For NCL overexpression or gene silencing, the cells were harvested by trypsinization at 24 hours after transfection with NCL-GFP or NCL siRNA, and then seeded in DMEM supplemented with $0.5 \%$ FCS. The colony number was counted after fixing with paraformaldehyde and staining with crystal violet in $10 \%$ buffer formalin. 


\section{Statistical analysis}

Data were expressed as the mean \pm standard deviations (SD) of at least three independent experiments. Comparisons between groups of independent samples were assessed by the student's $t$-test, one-way ANOVA, Mann-Whitney $U$ test or the Kruskal-Wallis test. The associations between categorical variables were assessed using the Chi-square test or Fisher's Exact test. Survival rates were calculated by the Kaplan-Meier methods and the difference in survival was compared with the log-rank test. The influence of various clinicopathological features on overall survival was assessed by the Cox proportional hazard model. A $P$-value $<0.05$ was considered statistically significant.

\section{ACKNOWLEDGMENTS}

We thank Chang Gung Medical Foundation Kaohsiung Chang Gung Memorial Hospital Tissue Bank (CLRPG8B0031) for technical support.

\section{COMPETING INTERESTS}

None related to the content of this article.

\section{FINANCIAL SUPPORT}

This work was supported by grants from the Ministry of Science and Technology, Taiwan (NSC 102-2320-B-110-001, MOST 103-2320-B-110-003-MY3 and MOST 103-2325-B-110-002), Chang Gung Memorial Hospital, Taiwan (NMRPG896143), the Kaohsiung Veterans General Hospital, Taiwan (VGHNSU102-002 and VGHNSU103-003), the Center for Neuroscience, National Sun Yat-Sen University and National Sun Yat Sen University-Kaohsiung Medical University Joint Research Center, Taiwan (KMU-TP103G01).

\section{Abbreviations}

HCC, hepatocellular carcinoma; HDGF, hepatoma-derived growth factor; NCL, nucleolin, PI3K, phosphatidylinositol 3-kinase; $\alpha \mathrm{FP}$, alpha-fetoprotein; siRNA, small interfering RNA; LC-MS/MS, liquid chromatography tandem mass spectrometry; co-IP, co-immunoprecipitation; qRT-PCR, quantitative reverse transcription-polymerase chain reaction.

\section{REFERENCES}

1. Huynh H, Chow PK, Tai WM, Choo SP, Chung AY, Ong HS, Soo KC, Ong R, Linnartz R, Shi MM. Dovitinib demonstrates antitumor and antimetastatic activities in xenograft models of hepatocellular carcinoma. J Hepatol. 2012; 56:595-601.

2. Nakamura $H$, Izumoto $Y$, Kambe $H$, Kuroda $T$, Mori $T$, Kawamura K, Yamamoto H, Kishimoto T. Molecular cloning of complementary DNA for a novel human hepatoma-derived growth factor. Its homology with high mobility group-1 protein. J Biol Chem. 1994; 269:25143-25149.

3. Kishima Y, Yoshida K, Enomoto H, Yamamoto M, Kuroda T, Okuda Y, Uyama H, Nakamura H. Antisense oligonucleotides of hepatoma-derived growth factor (HDGF) suppress the proliferation of hepatoma cells. Hepatogastroenterology. 2002; 49:1639-1644.

4. Hu TH, Huang CC, Liu LF, Lin PR, Liu SY, Chang HW, Changchien CS, Lee CM, Chuang JH, Tai MH. Expression of hepatoma-derived growth factor in hepatocellular carcinoma. Cancer. 2003; 98:1444-1456.

5. Chen SC, Kung ML, Hu TH, Chen HY, Wu JC, Kuo HM, Tsai HE, Lin YW, Wen ZH, Liu JK, Yeh MH, Tai MH. Hepatoma-derived growth factor regulates breast cancer cell invasion by modulating epithelial-mesenchymal transition. J Pathol. 2012; 228:158-169.

6. Iwasaki T, Nakagawa K, Nakamura H, Takada Y, Matsui K, Kawahara K. Hepatoma-derived growth factor as a prognostic marker in completely resected non-small-cell lung cancer. Oncol Rep. 2005; 13:1075-1080.

7. Hu TH, Lin JW, Chen HH, Liu LF, Chuah SK, Tai MH. The expression and prognostic role of hepatoma-derived growth factor in colorectal stromal tumors. Dis Colon Rectum. 2009; 52:319-326.

8. Chang KC, Tai MH, Lin JW, Wang CC, Huang CC, Hung $\mathrm{CH}$, Chen $\mathrm{CH}$, Lu SN, Lee CM, Changchien CS, $\mathrm{Hu}$ TH. Hepatoma-derived growth factor is a novel prognostic factor for gastrointestinal stromal tumors. Int J Cancer. 2007; 121:1059-1065.

9. Uyama H, Tomita Y, Nakamura H, Nakamori S, Zhang B, Hoshida Y, Enomoto H, Okuda Y, Sakon M, Aozasa K, Kawase I, Hayashi N, Monden M. Hepatoma-derived growth factor is a novel prognostic factor for patients with pancreatic cancer. Clin Cancer Res. 2006; 12:6043-6048.

10. Hsu SS, Chen CH, Liu GS, Tai MH, Wang JS, Wu JC, Kung ML, Chan EC, Liu LF. Tumorigenesis and prognostic role of hepatoma-derived growth factor in human gliomas. J Neurooncol. 2012; 107:101-109.

11. Lin YW, Li CF, Chen HY, Yen CY, Lin LC, Huang CC, Huang HY, Wu PC, Chen CH, Chen SC, Tai MH. The expression and prognostic significance of hepatoma-derived growth factor in oral cancer. Oral Oncol. 2012; 48:629-635.

12. Kao YH, Chen CL, Jawan B, Chung YH, Sun CK, Kuo SM, Hu TH, Lin YC, Chan HH, Cheng KH, Wu DC, Goto S, Cheng YF, Chao D, Tai MH. Upregulation of hepatoma-derived growth factor is involved in murine hepatic fibrogenesis. J Hepatol. 2010; 52:96-105. 
13. Yamamoto S, Tomita Y, Hoshida Y, Takiguchi S, Fujiwara Y, Yasuda T, Doki Y, Yoshida K, Aozasa K, Nakamura H, Monden M. Expression of hepatoma-derived growth factor is correlated with lymph node metastasis and prognosis of gastric carcinoma. Clin Cancer Res. 2006; 12:117-122.

14. Cheng C, Trzcinski O, Doering LC. Fluorescent labeling of dendritic spines in cell cultures with the carbocyanine dye "DiI". Front Neuroanat. 2014; 8:30.

15. Li Y, Song Y, Zhao L, Gaidosh G, Laties AM, Wen R. Direct labeling and visualization of blood vessels with lipophilic carbocyanine dye DiI. Nat Protoc. 2008; 3:1703-1708.

16. Wang CH, Davamani F, Sue SC, Lee SC, Wu PL, Tang FM, Shih C, Huang TH, Wu WG. Cell surface heparan sulfates mediate internalization of the PWWP/HATH domain of HDGF via macropinocytosis to fine-tune cell signalling processes involved in fibroblast cell migration. Biochem J. 2011; 433:127-138.

17. Hovanessian AG, Soundaramourty C, El Khoury D, Nondier I, Svab J, Krust B. Surface expressed nucleolin is constantly induced in tumor cells to mediate calciumdependent ligand internalization. PLoS One. 2010; 5:e15787.

18. Kung ML, Tsai HE, Hu TH, Kuo HM, Liu LF, Chen SC, Lin PR, Ma YL, Wang EM, Liu GS, Liu JK, Tai MH. Hepatoma-derived growth factor stimulates podosome rosettes formation in $\mathrm{NIH} / 3 \mathrm{~T} 3$ cells through the activation of phosphatidylinositol 3-kinase/Akt pathway. Biochem Biophys Res Commun. 2012; 425:169-176.

19. Bremer S, Klein K, Sedlmaier A, Abouzied M, Gieselmann V, Franken S. Hepatoma-derived growth factor and nucleolin exist in the same ribonucleoprotein complex. BMC Biochem. 2013; 14:2.

20. Huang Y, Shi H, Zhou H, Song X, Yuan S, Luo Y. The angiogenic function of nucleolin is mediated by vascular endothelial growth factor and nonmuscle myosin. Blood. 2006; 107:3564-3571.

21. Said EA, Krust B, Nisole S, Svab J, Briand JP, Hovanessian AG. The anti-HIV cytokine midkine binds the cell surface-expressed nucleolin as a low affinity receptor. J Biol Chem. 2002; 277:37492-37502.

22. Destouches D, El Khoury D, Hamma-Kourbali Y, Krust B, Albanese P, Katsoris P, Guichard G, Briand JP, Courty J, Hovanessian AG. Suppression of tumor growth and angiogenesis by a specific antagonist of the cell-surface expressed nucleolin. PLoS One. 2008; 3:e2518.

23. Joo EJ, Yang H, Park Y, Park NY, Toida T, Linhardt RJ, Kim YS. Induction of nucleolin translocation by acharan sulfate in A549 human lung adenocarcinoma. J Cell Biochem. 2010; 110:1272-1278.

24. Said EA, Courty J, Svab J, Delbe J, Krust B, Hovanessian AG. Pleiotrophin inhibits HIV infection by binding the cell surface-expressed nucleolin. Febs J. 2005; 272:4646-4659.
25. Shi H, Huang Y, Zhou H, Song X, Yuan S, Fu Y, Luo Y. Nucleolin is a receptor that mediates antiangiogenic and antitumor activity of endostatin. Blood. 2007; 110:2899-2906.

26. Moura V, Lacerda M, Figueiredo P, Corvo ML, Cruz ME, Soares R, de Lima MC, Simoes S, Moreira JN. Targeted and intracellular triggered delivery of therapeutics to cancer cells and the tumor microenvironment: impact on the treatment of breast cancer. Breast Cancer Res Treat. 2012; 133:61-73.

27. Joo EJ, ten Dam GB, van Kuppevelt TH, Toida T, Linhardt RJ, Kim YS. Nucleolin: acharan sulfate-binding protein on the surface of cancer cells. Glycobiology. 2005; 15:1-9.

28. Lottin-Divoux S, Jean D, Le Romancer M, Frade R. Activation of Epstein-Barr virus/C3d receptor (gp140, CR2, $\mathrm{CD} 21$ ) on human B lymphoma cell surface triggers $\mathrm{Cbl}$ tyrosine phosphorylation, its association with $\mathrm{p} 85$ subunit, Crk-L and Syk and its dissociation with Vav. Cell Signal. 2006; 18:1219-1225.

29. Di Segni A, Farin K, Pinkas-Kramarski R. Identification of nucleolin as new ErbB receptors-interacting protein. PLoS One. 2008; 3:e2310.

30. Tate A, Isotani S, Bradley MJ, Sikes RA, Davis R, Chung LW, Edlund M. Met-Independent Hepatocyte Growth Factor-mediated regulation of cell adhesion in human prostate cancer cells. BMC Cancer. 2006; 6:197.

31. Krust B, El Khoury D, Nondier I, Soundaramourty C, Hovanessian AG. Targeting surface nucleolin with multivalent HB-19 and related Nucant pseudopeptides results in distinct inhibitory mechanisms depending on the malignant tumor cell type. BMC Cancer. 2011; 11:333.

32. Pichiorri F, Palmieri D, De Luca L, Consiglio J, You J, Rocci A, Talabere T, Piovan C, Lagana A, Cascione L, Guan J, Gasparini P, Balatti V, Nuovo G, Coppola V, Hofmeister CC, et al. In vivo NCL targeting affects breast cancer aggressiveness through miRNA regulation. J Exp Med. 2013; 210:951-968.

33. Ridley L, Rahman R, Brundler MA, Ellison D, Lowe J, Robson K, Prebble E, Luckett I, Gilbertson RJ, Parkes S, Rand V, Coyle B, Grundy RG. Multifactorial analysis of predictors of outcome in pediatric intracranial ependymoma. Neuro Oncol. 2008; 10:675-689.

34. Mourmouras V, Cevenini G, Cosci E, Epistolato MC, Biagioli M, Barbagli L, Luzi P, Mannucci S, Miracco C. Nucleolin protein expression in cutaneous melanocytic lesions. J Cutan Pathol. 2009; 36:637-646.

35. Qiu W, Zhou F, Zhang Q, Sun X, Shi X, Liang Y, Wang X, Yue L. Overexpression of nucleolin and different expression sites both related to the prognosis of gastric cancer. Apmis. 2013; 121:919-925.

36. Reyes-Reyes EM, Teng Y, Bates PJ. A new paradigm for aptamer therapeutic AS1411 action: uptake by macropinocytosis and its stimulation by a 
nucleolin-dependent mechanism. Cancer Res. 2010; 70:8617-8629.

37. Tsai YP, Yang MH, Huang CH, Chang SY, Chen PM, Liu CJ, Teng SC, Wu KJ. Interaction between HSP60 and beta-catenin promotes metastasis. Carcinogenesis. 2009; 30:1049-1057.

38. Lee $\mathrm{TH}$, Chen $\mathrm{CH}$, Suizu F, Huang $\mathrm{P}$, Schiene-Fischer C, Daum S, Zhang YJ, Goate A, Chen RH, Zhou XZ, Lu KP. Death-associated protein kinase 1 phosphorylates Pin1 and inhibits its prolyl isomerase activity and cellular function. Mol Cell. 2011; 42:147-159.

39. Cheng TS, Hsiao YL, Lin CC, Yu CT, Hsu CM, Chang MS, Lee CI, Huang CY, Howng SL, Hong YR.
Glycogen synthase kinase 3beta interacts with and phosphorylates the spindle-associated protein astrin. J Biol Chem. 2008; 283:2454-2464.

40. Jerke U, Tkachuk S, Kiyan J, Stepanova V, Kusch A, Hinz M, Dietz R, Haller H, Fuhrman B, Dumler I. Stat1 nuclear translocation by nucleolin upon monocyte differentiation. PLoS One. 2009; 4:e8302.

41. Christian S, Pilch J, Akerman ME, Porkka K, Laakkonen P, Ruoslahti E. Nucleolin expressed at the cell surface is a marker of endothelial cells in angiogenic blood vessels. J Cell Biol. 2003; 163:871-878. 